mean $\mathrm{pH}$ of $7 \cdot 15$. At the same time the trace of twin two began to show late decelerations (fig. 4).

Thirty minutes later a lower segment caesarean section was carried out. At delivery the first twin had a mean venous cord blood pH of 7.09 and a heart rate of 50 beats/min. After intubation with intermittent positive pressure ventilation for two minutes the baby responded well, and the Apgar score at five minutes was nine. It was a female and weighed $2,130 \mathrm{~g}$.

The second twin was transverse and was also in poor condition at birth with a mean venous cord blood $\mathrm{pH}$ of $7 \cdot 10$. It responded well to intubation and intermittent positive pressure ventilation and recovered in two minutes. It was also female and weighed $2,210 \mathrm{~g}$. The placenta was monochorionic to macroscopic examination and the twins were therefore likely to be identical. There was no evidence of joint placental circulation. The maternal venous blood $\mathrm{pH}$ at the time of section was $7 \cdot 36$.

Both babies were kept in the special care baby unit for 36 hours and made good progress. Mother and babies were discharged home well on the 13th postoperative day.

\section{Discussion}

These cases illustrate the advantages of monitoring both fetuses in labour. In the first case only continuous fetal heart rate monitoring would have given early enough indication of rapidly developing distress in the second twin to save it by caesarean section.

In the second case, though caesarean section was primarily for the first twin, it was evident that the second twin was also unlikely to withstand the stress of delivery, particularly with the inevitable delay after delivery of the first.

\section{References}

Gerber, J. A., Choithani, H., and O'Leary, J. A. (1969). Obstetrics and Gynecology, 33, 770 .

Morison, J. E. (1970). In Foetal and Neonatal Pathology, 3rd edn., p. 184. London, Butterworths.

Rausen, A. R., Seki, M., and Strauss, L. (1965). Fournal of Pediatrics, 66, 613

\title{
End of the Trend? A I2-year Study of Age at Menarche
}

\author{
T. C. DANN, D. F. ROBERTS
}

British Medical Fournal, 1973, 3, 265-267

\section{Summary}

A 12-year study of menarchial age in all girls entering the University College of Swansea (1959-70) suggests that the downward trend in age at menarche has ceased in Britain. The turning point appears to have occurred in girls born about 1946.

\section{Introduction}

By the mid-1950s it was established that in girls in Britain, as elsewhere in Europe, menarche had been occurring at steadily earlier ages over the past 100 years. The rate of this secular diminution in age of menarche was calculated to be about three to four months per decade (Tanner, 1955). The continuation of this trend was shown by Tanner (1962, 1965) with critical documentation, and various factors responsible for it were identified. It seemed to us to be highly unlikely that this diminution would continue indefinitely and therefore that it would be of interest to keep a check on menarchial age in an attempt to detect the first signs of any slackening of the trend in Britain. While to do this thoroughly would necessitate a large scale investigation, we felt that it would be useful nonetheless to initiate a small sample inquiry. In 1959 we therefore started to collect information on all girls entering the University College of Swansea in each year. The material accumulated to date thus consists of recall data from a succession of cross-sectional surveys relating to one particular section of the population.

\section{Subjects and Methods}

In the medical examinations carried out on all girls at the time of their admission to the University College of Swansea

University of Warwick, Coventry

T. C. DANN, M.A., M.D., D.OBST.R.C.O.G., Medical Officer

University of Newcastle upon Tyne, Newcastle upon Tyne, NE2 4AA D. F. ROBERTS, M.A., D.PHIL., Reader in Human Genetics from 1959 onwards the age at menarche was recorded. The 1970 intake was the last to be included in this study, and, with the exception of the 1963 intake for which this item was omitted, the data are continuous over 12 years. Each girl was asked when her menarche had occurred. Such recall data are notoriously liable to error or bias from a variety of sources, summarized for example by Roberts and Dann (1967). They depend on recollection accuracy, intelligence of the girl, composition of the sample in terms of age and pubertal status, and the clarity of definition of the event. Such errors are thought to be minimal in the present data, for the sample relates to girls above average in intelligence and reliability of memory, all questioned between the ages of 18 and 21. There was no girl who had not attained menarche at the time of examination. Most of the girls were quite clear in recalling the quarter or the actual month, though the data were recorded as age at birthday preceding menarche for ease of analysis. The few girls whose answers indicated that they themselves were in some doubt were excluded from the analysis. Other relevant details were also noted on the total of over 2,400 girls and the following variables were incorporated in the analysis: menarchial age in years, recorded as age at birthday preceding; year of birth; the number of siblings the girl has, and her numerical position in her sibship; the father's occupation described numerically as in the Registrar General's classification.

\section{Results}

The data for the first seven years (intakes of 1959-65) were analysed and published (Roberts and Dann, 1967; Dann and Roberts, 1969). This first analysis showed a clear and progressive diminution in menarchial age which was highly significant. Its rate was compatible with that calculated by Tanner (1965) from European studies over the last century and from American studies since the beginning of the 20th century. Effects were also shown of family size, position in family, and physique of the girl. Later menarche tended to occur in girls from larger families, of later position in sibship, and of more linear physique. But clearly there was no evidence in that first analysis suggesting cessation of the secular trend. 
The results for the whole 12 years of the study to 1970 have now been analysed (fig. 1). It is particularly striking that menarchial age seems to have stopped its downward trend. The earliest mean occurred in the 1964 entry, and all means for subsequent years have shown higher values. A

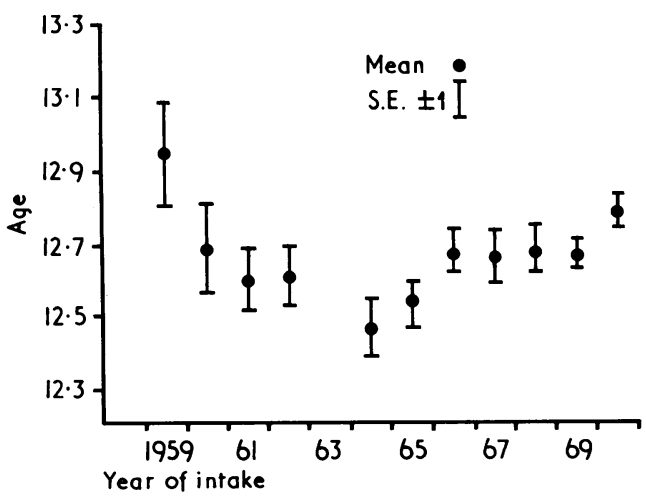

FIG. 1-Age at birthday preceding menarche in Swansea students.

regression line, ${ }^{*}$ taking into account the effect of all variables, has been fitted to these data (fig. 2); the curvilinear component is significant statistically at $5 \%$. The lowest point on the curve occurs in girls born about 1946, the 1965 intake. If instead of a curvilinear regression a linear regression is fitted then the secular regression line is nearly horizontal, suggesting again no downward secular trend.

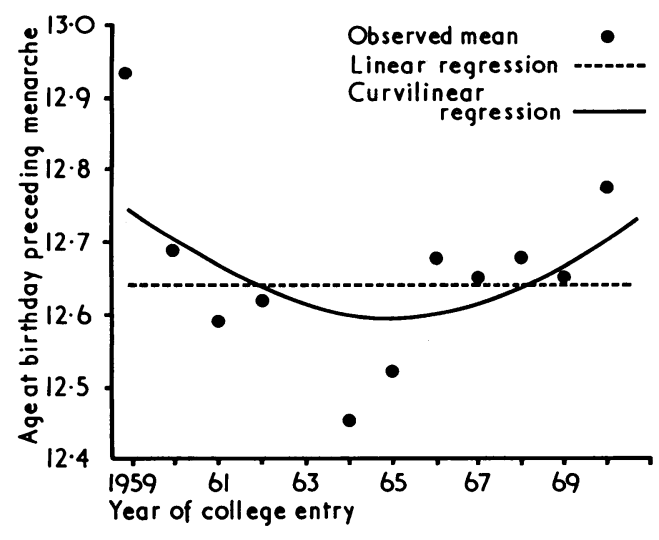

FIG. 2-Regression lines of age at birthday preceding menarche on year of college entry.

These data are open to the criticism that they are retrospective and cross-sectional, and liable to recollection error. From the nature of the present sample it is thought that such errors are minimal, and it is in any case not easy to see how they could account for the apparent regularity of the findings. The alternative method of data collection, by examination of the status quo on large samples of girls and subsequent analysis by probits, does not suffer from the same drawbacks. Results from the two types of investigation are not directly comparable, but the one may be adjusted to make it more comparable with the other. This is done in fig. 3 where the age scale represents the true age of menarche, not

* $\quad \mathrm{Y}=12.990-.073 \mathrm{X}_{1}+.005\left(\mathrm{X}_{1}\right)^{2}+\cdot 123 \mathrm{X}_{2}-\cdot 135 \mathrm{X}_{\mathrm{3}}-.017 \mathrm{X}_{4}$ where $\mathrm{X}_{1}=$ year of birth less 1938

$\mathrm{X}_{2}=$ the number of siblings the girl has

$X_{2}=$ the numerical position of the girl in her sibship

$\mathbf{X}_{\mathbf{4}}=$ the father's occupation described numerically as in the Registrar General's classification. age at birthday preceding, and the results of the present survey are superimposed on results of studies made in Britain by status quo methods and probit analysis. Despite the special nature of our student sample there is remarkable concordance over the first part of our study. The only published recent probit analysis of a British sample (Roberts et al., 1971) relates to a relatively poor industrial community

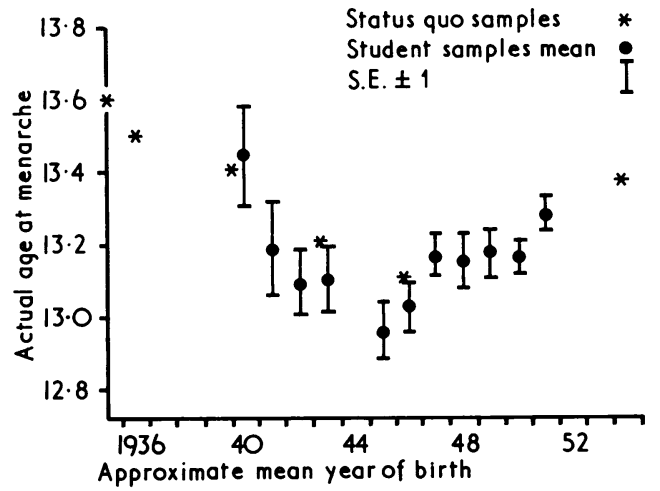

FIG. 3-Secular trend in menarche in Britain (recall samples are age corrected).

difficult to compare with the other samples, and its apparent concordance with the present findings clearly requires further examination. Further surveys using status quo methods are highly desirable to establish whether the former trend has ceased, and whether the present tendency is for menarchial age to remain constant or to be retarded, as the present results suggest. We are indebted to Professor J. M. Tanner for informing us that data as yet unpublished on a recent London series indicate a mean menarchial age very similar to that observed in 1959.

Any conclusion on a limited series of small samples spanning a limited period of time such as this is tentative, and it is important that data continue to be collected. However, the pattern shown by the results of this 12-year investigation is remarkably consistent. Further analysis of our data is obviously essential to ascertain that the apparent secular changes seen here are not due to other factors-for example, it is possible that there may be differences in menarchial age in different geographical areas or social segments of the population of this country, and consistent changes in their representation in the Swansea student intake could produce apparent secular variation. There is indeed a slight upward trend in socioeconomic status as defined by father's occupation over the whole period, but in the data there is no significant correlation of menarchial age with this variable, and in any case, though it might be involved in the decline in the early part of our series, it would not account for the apparent retardation in menarchial age in the last five years. Over the 12 years of the study there has also occurred a steady diminution in the proportion of students from industrial South Wales, and an increase from northern and south-east England. The only county sufficiently represented to allow an intra-county analysis-Glamorgan, providing 609 students -shows a U-shaped pattern of mean menarchial age similar to the total series.

These results are presented on account of their intrinsic interest, with full awareness of their tentative nature. But the suggestion that the secular downward trend in menarchial age in Britain may have halted, at least temporarily, is compatible with what has been observed in studies of maturation in the United States (Zacharias et al., 1970); studies elsewhere in north-west Europe suggest that the trend is also coming to a halt (Brundtland and Walløe, 1973), 
though in eastern Europe it still appears to be in progress (Eiben, 1972).

\section{References}

Brundtland, G. H., and Walløe, L. (1973). Nature, 241, 478.
Dann, T. C., and Roberts, D. F. (1969). British fournal of Preventive and Social Medicine, 23, 65 .

Eiben, O. G. (1972). Anthropologischer Anzeiger, 33, 205.
Roberts, D. F., and Dann, T. C. (1967). British fournal of Preventive and Social Medicine, 21, 170 .

Roberts, D. F., Rozner, L. M., and Swan, A. V. (1971). Acta Paediatrica Scandinavica, 60, 158 .

Tanner, J. M. (1955). Growth at Adolescence, 1st edn. Oxford, Blackwell Scientific

Tanner, J. M. (1962). Growth at Adolescence, 2nd edn. Oxford, Blackwell Scientific.

Tanner, J. M. (1965). In Biological Aspects of Social Problems, ed. J. E. Meade and A. S. Parkes, Edinburgh, Oliver and Boyd.

Zacharias, L., Wurtman, R. J., and Schatzoff, M. (1970). American fournal of Obstetrics and Gynaecology, 108, 833.

\title{
Renal Puncture in Infancy
}

\author{
H. M. SAXTON, J. S. CAMERON, C. CHANTLER, C. S. OGG
}

British Medical fournal, 1973, 3, 267-270

\section{Summary}

Renal puncture was used in the diagnosis of five infants with suspected cystic disease of the kidney. This technique is simple and it may provide information that may otherwise be difficult to obtain.

\section{Introduction}

The use of diagnostic renal puncture in children and adults is now well established. Apart from puncture for renal biopsy the commonest use is in the diagnosis of simple renal cysts (Lindblom, 1946; Sherwood and Stevenson, 1971). It has also been used to confirm the presence and define the nature of obstruction of the upper urinary tract (Weens and Florence, 1954; Wickbom, 1954; Sherwood and Stevenson, 1972) and to produce temporary drainage of an obstructed kidney (Ogg et al., 1969; Saxton et al., 1972). While the use of renal puncture for antegrade pyelography during infancy has been described (Lalli, 1969) it is still uncommon, and renal puncture does not so far appear to have been used in the diagnosis of cystic disease sof the kidney at this age. We are therefore presenting our experience with five infants in whom renal puncture was used as a diagnostic aid. Four cases suffered from renal failure and a fifth had a non-functioning kidney.

\section{Case Reports}

Case 1.-Female infant born at full term by a normal delivery. Did not cry at birth and was cyanosed. Chest $x$-ray picture showed a left pneumothorax which was aspirated. Seven days after birth the blood urea was found to be $168 \mathrm{mg} / 100 \mathrm{ml}$ and she was transferred to Guy's Hospital. Her head was small, but the ears were normal. There was oedema of the lower limbs, and the kidneys were easily palpable. Intravenous urography showed no excretion of contrast, but there was a vaguely defined right kidney. Renal puncture on the left revealed multiple cysts, some intercommunicating (fig. 1). No filling of the collecting system was achieved. A diagnosis of multicystic renal disease was made. At no stage was any urine passed. The blood urea rose, and two days after admission she died. Necropsy showed

\footnotetext{
Departments of Radiology, Medicine, and Paediatrics, Guy's
Hospital, London SE1 9RT

H. M. SAXTON, F.R.C.P., F.F.R., Consultant Radiologist

J. S. CAMERON, M.D., F.R.C.P., Senior lecturer in Medicine and Renal Physician

C. CHANTLER, M.D., M.R.C.P., Consultant Paediatrician

C. S. OGG, M.D., M.R.C.P., Renal Physician
}

changes in the lungs consistent with hyaline membrane disease. There were no cysts in the lungs or liver. The kidneys were large with numerous cysts. Some parenchyma was found between the cysts but no calyces or papillae were seen. Microscopy showed that the renal tissue contained cartilage and metanephric tubular elements. Many tubules were dilated. The lower ureters were normal but the upper ureters were dilated with frail transparent walls.

Case 2.-Male infant. Admitted 14 hours after birth because of difficulty with breathing and cyanotic attacks. He was cyanosed with bilaterally diminished air entry and was found to have bilateral pneumothoraces. There was a single palmar crease and widely splayed toes. A prominent medial epicanthic fold was noted extending down-

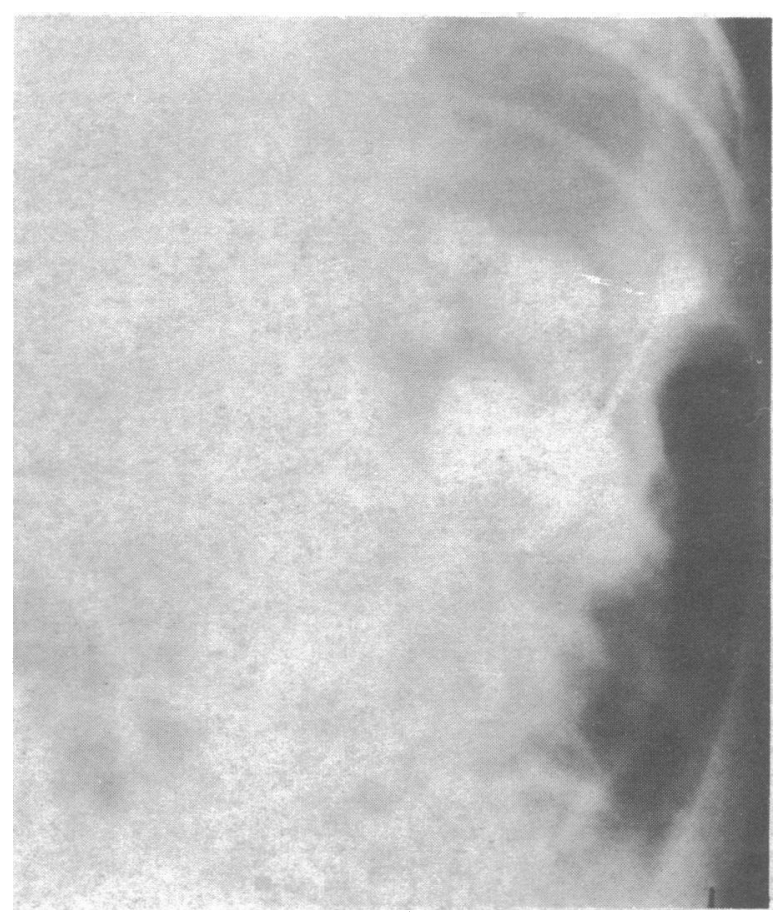

FIG. 1-Case 1. Left renal puncture with injection of contrast. Injection into two cystic areas has produced filling of multiple renal cysts due to intercommunication between cysts.

wards beneath the eye on to the upper cheek. The ears were normal. A right-sided intercostal drain was inserted. During the next 36 hours he did not pass urine, and intravenous urography two days after admission showed no excretion of contrast and a faint renal outline on the right side. Blood urea at this stage was $66 \mathrm{mg} / 100 \mathrm{ml}$. An attempt was then made to needle the kidneys, but at no stage was a 